\title{
Antixenosis component of resistance to sorghum midge, Contarinia sorghicola Coq. in Sorghum bicolor (L.) Moench
}

\author{
By H C SHARMA and P VIDYASAGAR \\ International Crops Research Institute for the Semi-Arid Tropics (ICRISAT), \\ Patancheru, Andhra Pradesh 502 324, India
}

(Accepted 6 January 1994)

\begin{abstract}
Summary
Sorghum midge, Contarinia sorghicola Coq. (Diptera: Cecidomyiidae) is the most destructive pest of grain sorghum, and host-plant resistance is an effective method of controlling this insect. We studied the antixenosis component of resistance to sorghum midge using multi-, double- and no-choice cage tests, and under multi-choice field conditions to quantify and understand the nature of antixenosis component of resistance to this insect in Sorghum bicolor (L.) Moench. Midge response towards sorghum panicles was influenced by panicle size and cage type used to study the orientation behaviour. Maximum number of midges were recorded at 30 and $60 \mathrm{~min}$ after initiating the experiment. Antixenosis shown by $C$. sorghicola under multi-choice field conditions to ICSV 197 and TAM 2566 was not confirmed under cage tests, while DJ 6514, AF 28 and IS 3461 were non-preferred both under field and cage conditions. Midgeresistant female parents (PM 7061 and PM 7068) were less preferred than the midge susceptible (ICSA 42 and 296A) female parents. Male-sterility did not influence host finding and acceptance by the midge females, although in one out of two tests, the maintainer lines (B-lines) were preferred over the male-sterile lines (A-lines).
\end{abstract}

Key words: Antixenosis, plant resistance, preference, sorghum midge, Contarinia sorghicola, Sorghum bicolor

\section{Introduction}

Sorghum midge, Contarinia sorghicola Coq. (Diptera: Cecidomyiidae), is the most destructive pest of grain sorghum worldwide (Harris, 1976), and host-plant resistance is an effective and economic means of controlling this pest. Considerable progress has been made in screening and breeding for host-plant resistance to $C$. sorghicola (Johnson, Rosenow \& Teetes, 1973; Wiseman, McMillian \& Widstrom, 1973; Singh, 1987; Wiseman, Duncan \& Widstrom, 1988; Peterson, Johnson, Teetes \& Rosenow, 1988).

Midge females mate soon after emergence and lay the eggs inside flowering sorghum spikelets. The larvae suck the sap of the developing ovary which remains undeveloped, resulting in the production of chaffy spikelets. The female midge has a life span of less than $24 \mathrm{~h}$, and during this period, it has to locate flowering sorghum panicles for oviposition. Eggs are laid only in spikelets at anthesis. Flowering in sorghum panicles is completed in 4 to 6 days. Visual and chemical stimuli emitted by the sorghum panicle guide the insect to its host, and physico-chemical stimuli from the viable pollen and receptive stigmas govern the oviposition process (Sharma, Leuschner \& Vidyasagar, 1990a). 
Cultivar antixenosis (non-preference) by the visiting adults (Wiseman \& McMillian, 1968; Sharma et al., 1988a , 1990a), morphological barriers to oviposition (Bergquist, Rotar \& Mitchell, 1974; Rossetto, Goncalves \& Diniz, 1975; Waquil, Teetes \& Peterson, 1986a; Sharma, Vidyasagar \& Leuschner, 1990b), and possibly antibiosis (Rossetto, 1985; Teetes \& Johnson, 1978; Waquil, Teetes \& Peterson, 1986b; Sharma et al., 1990a,b) are the major components of resistance to sorghum midge. As midge-resistant genotypes have different combinations of resistance mechanisms (Sharma, Vidyasagar \& Leuschner, 1991), it is important to locate and quantify the contribution of different components of resistance in order to increase the levels and diversity of resistance.

Antixenosis by the adults has been considered to be one of the factors resulting in lower susceptibility to midge in some cultivars (Wiseman \& McMillian, 1968; Sharma et al., 1988a). However, these studies are based on multi-choice field conditions. Because of the day-to-day fluctuations in midge density and staggered flowering of sorghum cultivars over a period of time, the antixenosis component of resistance to $C$. sorghicola has not been quantified under uniform insect pressure and environmental conditions. In the present studies, we studied the antixenosis component of resistance to sorghum midge in diverse sources of resistance, and the newly developed midge-resistant cytoplasmic male-sterile lines under uniform midge density and environmental conditions. These results were compared with the relative preference observed under field conditions to identify cultivars with antixenosis component of resistance, and understand the contribution of this mechanism under multi-choice and no-choice conditions.

\section{Materials and Methods}

Studies were conducted on the effect of cage type and panicle size on the orientation behaviour of midge females, and the role of antixenosis component of resistance in a diverse array of sorghum cultivars under multi-, double- and no-choice conditions in the cage, and multi-choice field conditions. These studies were carried out between 1988-91 at the International Crops Research Institute for the Semi-Arid Tropics, Patancheru, Andhra Pradesh, India.

\section{Crop}

The crop was raised under rainfed conditions (June-October) during the rainy season, and under irrigated conditions during the post-rainy season (November-April). Test cultivars were planted on ridges, $4 \mathrm{~m}$ long and $75 \mathrm{~cm}$ apart. Carbofuran $3 \mathrm{G}$ was applied to the soil at the rate of $1.2 \mathrm{Kg}$ a.i./ ha at sowing to protect the crop against the sorghum shoot fly, Atherigona soccata Rondani. The seedlings were thinned 15 days after emergence; the spacing between the plants was $15 \mathrm{~cm}$. No insecticide was applied during the reproductive phase of the crop. During the post-rainy season, overhead sprinkler irrigation was used to increase the relative humidity to augment midge density (Sharma, Vidyasagar \& Leuschner, $1988 b)$.

\section{Multi-choice field conditions}

Antixenosis tests

Cultivar preference under field conditions was studied in terms of number of midge females/ 10 panicles in the central two rows for three consecutive days at flowering. Number of midges were recorded between $0900-1000 \mathrm{~h}$, when maximum midge activity occurs under field conditions (Sharma \& Vidyasagar, 1992). Midge numbers on each cultivar were recorded at the half-anthesis stage irrespective of the date of flowering of a cultivar. 


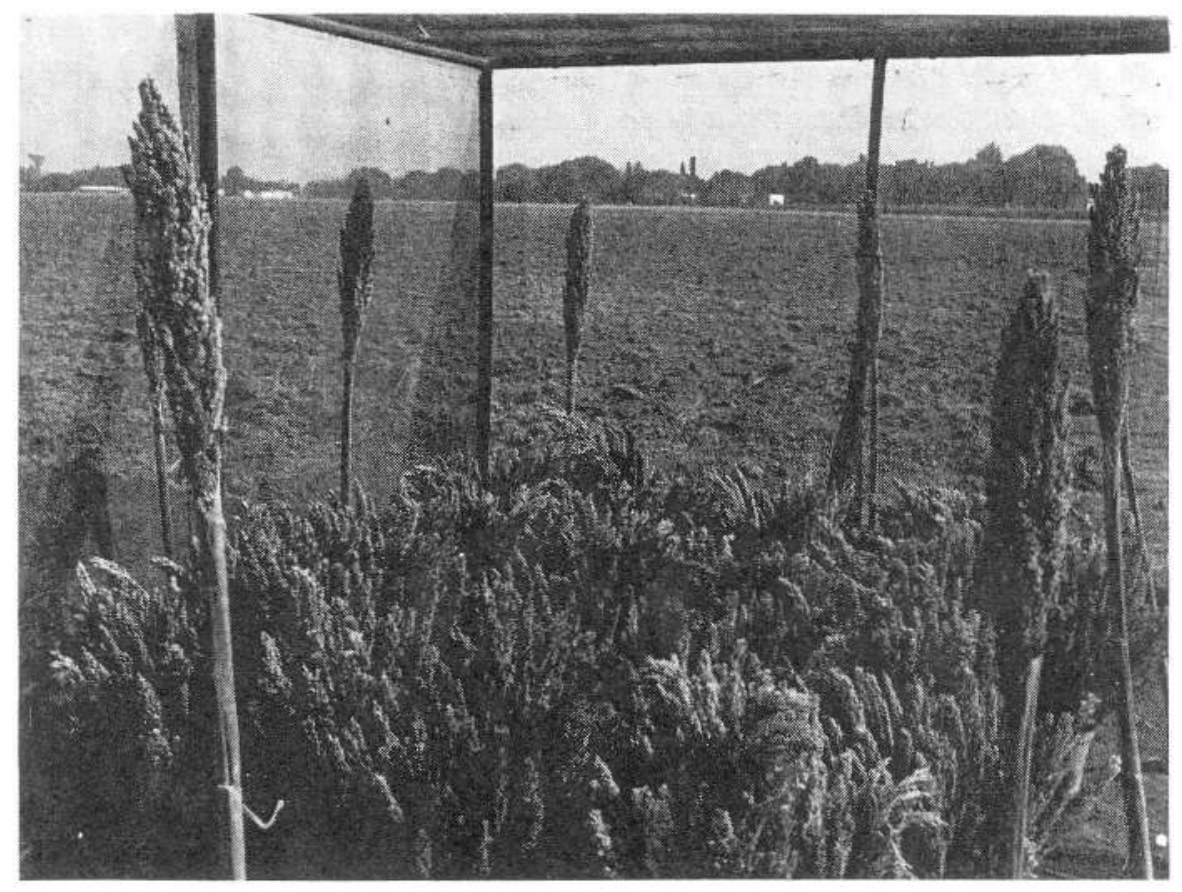

Fig. 1. Wooden mesh-screened cage used to study antixenosis by the sorghum midge under multi-choice conditions.

\section{Multi-choice cage tests}

Cultivar antixenosis by the midge females under multi-choice conditions was studied using a $1.5 \mathrm{~m} \times 2 \mathrm{~m} \times 1.5 \mathrm{~m}$ cage covered with a wire-mesh (Fig. 1). Midge-infested panicles excised at the milk stage ( 15 days after infestation), from which the adults were about to emerge in 1-2 days, were placed in 1 litre plastic jars containing water. Ten to 15 midgeinfested panicles were placed in each jar, and five such jars were kept in the centre of the cage, from which the midges emerged between 0700-1030 h. Panicles of the test cultivars were excised $45 \mathrm{~cm}$ below the tip at $0830 \mathrm{~h}$, and placed individually in $250 \mathrm{ml}$ conical flasks containing water. The panicles were held upright in the conical flasks by placing a cotton swab around the peduncle at the rim of the flask. Panicles were placed in a circular grid $50 \mathrm{~cm}$ away from the midge infested panicles. The adults that emerged from the infested panicles were allowed a free-choice for different test cultivars.

Each test was repeated 10 times, and the position of test cultivars was changed in each test to avoid position effects. The number of midges on the panicles of different cultivars was recorded at 30 and $60 \mathrm{~min}$ after initiating the experiment. All the tests were conducted between 0900 to $1030 \mathrm{~h}$.

\section{Double-choice tests}

Cultivar antixenosis by the midge females under double-choice conditions was studied in a cylindrical cage $(0.5 \mathrm{~m}$ diameter and $1.5 \mathrm{~m}$ high) framed with an iron bar (Fig. 2). The cage was covered with a thin blue georgette cloth bag. One side of the cloth bag had a $1 \mathrm{~m}$ opening which could be opened and closed with a Velcro ${ }^{\circledR}$ tape. Five such cages were placed in the field on level-ground in a row (in a north-south axis), and all the cages faced the sun at the same angle. Panicles of the test genotypes were excised in the morning at $50 \%$ flowering (when the midges select the host plant for oviposition), and placed individually in $250 \mathrm{ml}$ conical flasks containing water as described before. Panicles of the two test cultivars were placed in a north-south direction. 


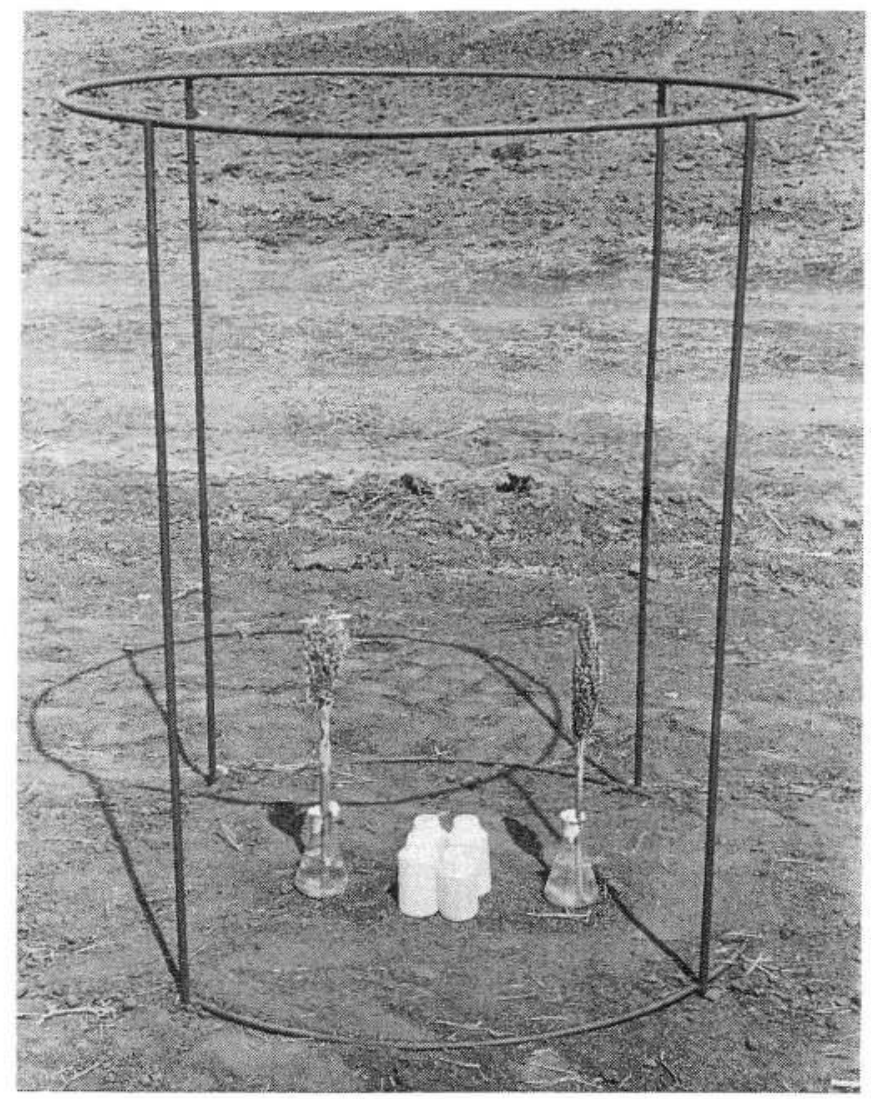

(a)

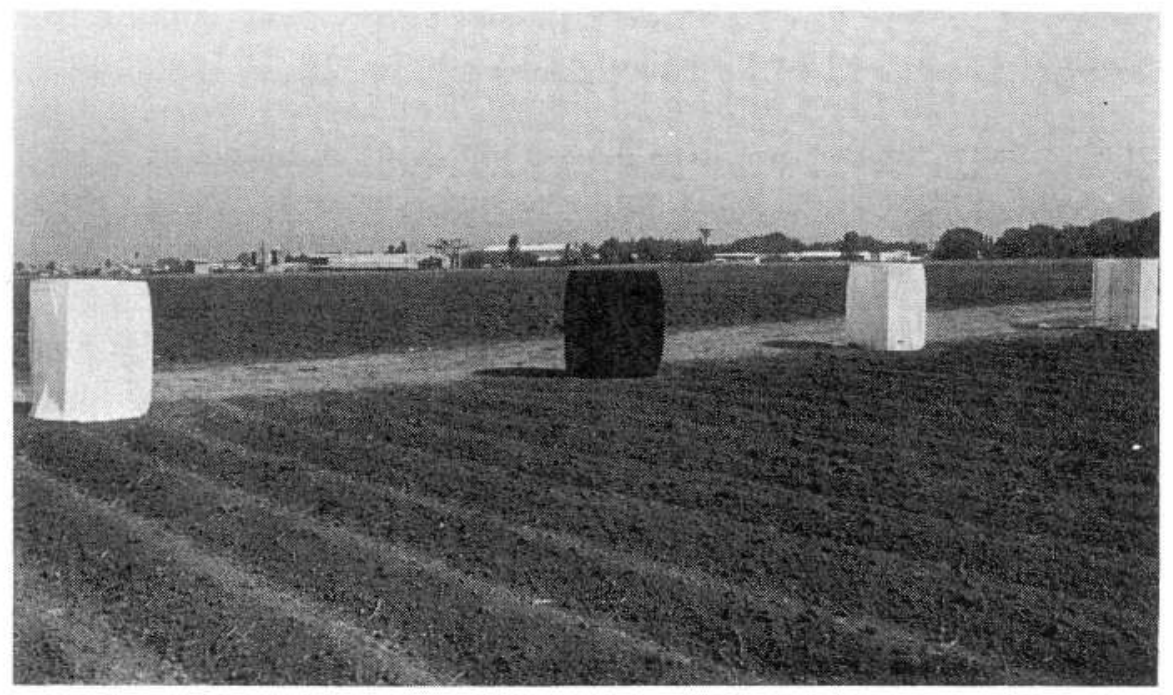

(b)

Fig. 2. Iron-bar framed cylindrical cage $(a)$ used to study antixenosis by the sorghum midge towards different sorghum genotypes, and $(b)$ wire frame covered with a cloth bag.

Midge females for double-choice tests were collected from flowering sorghum panicles between $0800-0900 \mathrm{~h}$ in plastic bottle aspirators (Sharma et al., 1988a). Twenty midge females were collected in each bottle, and one hundred insects were released inside each cage. Plastic bottles containing the midge females were placed in the centre of the cage, and the midges were allowed to come out and exercise their choice for the test cultivars. The number of midges responding to the panicles of different cultivars were recorded 30 
and $60 \mathrm{~min}$ after initiating the experiment. Each test was repeated 10 times. The position of the test cultivars was changed in each test to avoid position effects.

\section{No-choice tests}

No-choice tests were conducted under cylindrical cage as described above. In this case, only one panicle was placed in the centre of the cage, and the number of midges responding to the panicle were recorded 30 and $60 \mathrm{~min}$ after initiating the experiment. Each test was repeated 10 times. Antixenosis under no-choice conditions was studied for three cultivars.

\section{Effect of cage type and panicle size on the orientation behaviour of midge females}

Response of midge females to the panicles of CSH 1 and TAM 2566 was compared in a wooden mesh-screened cage $(1 \mathrm{~m} \times 1 \mathrm{~m} \times 1 \mathrm{~m})$ and the blue cloth covered cylindrical cage under double-choice conditions as described above. Number of midges on the panicles were recorded 30 and $60 \mathrm{~min}$ after initiating the experiment. Each test was repeated 10 times.

In another experiment, midge response to the large panicles having 20 branches, and small panicles having 10 branches was studied for CSH 1 and TAM 2566 in a two-choice test in the cylindrical cage as described above. The number of midges responding to the test cultivars was recorded at 15, 30,60 and 120 min after initiating the experiment. Small and large panicles of the same genotype were compared for midge response, and each test was repeated 10 times.

\section{Antixenosis in diverse sources of resistance to sorghum midge}

Five diverse sources of resistance to midge (IS 3461, IS 10712, TAM 2566, AF 28 and DJ 6514), two improved midge-resistant cultivars (ICSV 197 and ICSV 745), and three susceptible commercial cultivars (ICSV 112, CSH 1 and CSH 11) were tested for relative preference by the midge during the $1989-90$ rainy and post-rainy seasons. The test cultivars were planted in four row plots, $4 \mathrm{~m}$ long. There were three replications in a randomised complete block design.

Antixenosis was studied under multi-choice field and cage conditions as described earlier. Nine pairs of test cultivars were also compared for their relative preference under doublechoice conditions using the cylindrical cage. Three cultivars were tested under no-choice conditions.

\section{Effect of cytoplasmic male-sterility on antixenosis to midge}

During the 1989-91 seasons, two midge-resistant (PM 7061 and PM 7068) and two midgesusceptible (ICSA 42 and 296) female parents were compared for their relative preference under field and cage conditions. Each line was planted in eight row plots, $4 \mathrm{~m}$ long. There were two replications in a randomised complete block design.

Cultivar non-preference was studied under multi-choice field conditions. The number of midges/10 panicles was recorded as described earlier. The A-lines (male-sterile lines) and the maintainer lines (B-lines) were compared separately, and together under multi-choice conditions in the wire-mesh screened cage. The A and B pairs of the same parent were also compared in a double-choice test to evaluate the effect of cytoplasmic male-sterility on cultivar antixenosis to midge females. 


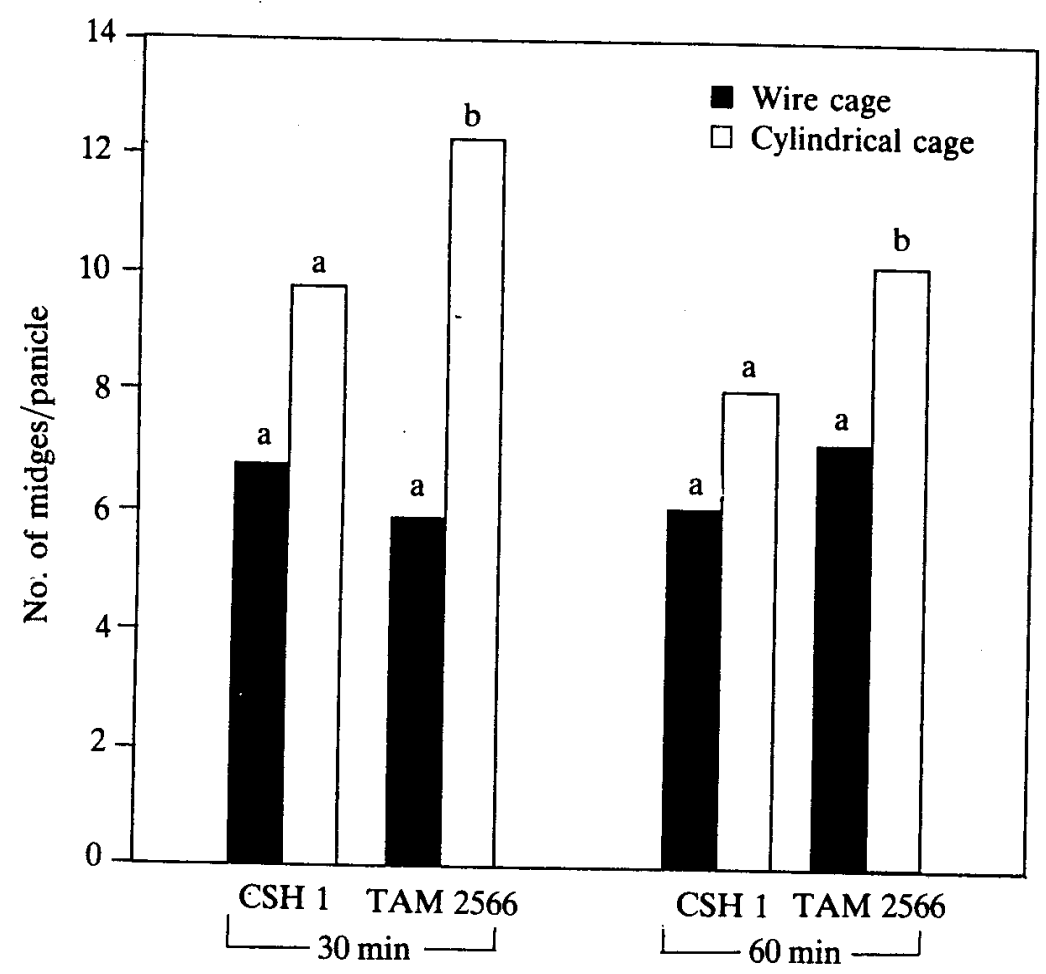

Fig. 3. Midge response towards panicles of CSH 1 and TAM 2566 under a wiremesh-screened wooden cage and iron-bar framed cylindrical cage covered with a blue cloth bag. A pair of bars followed by the same letter are not significantly different at $P=0.05$.

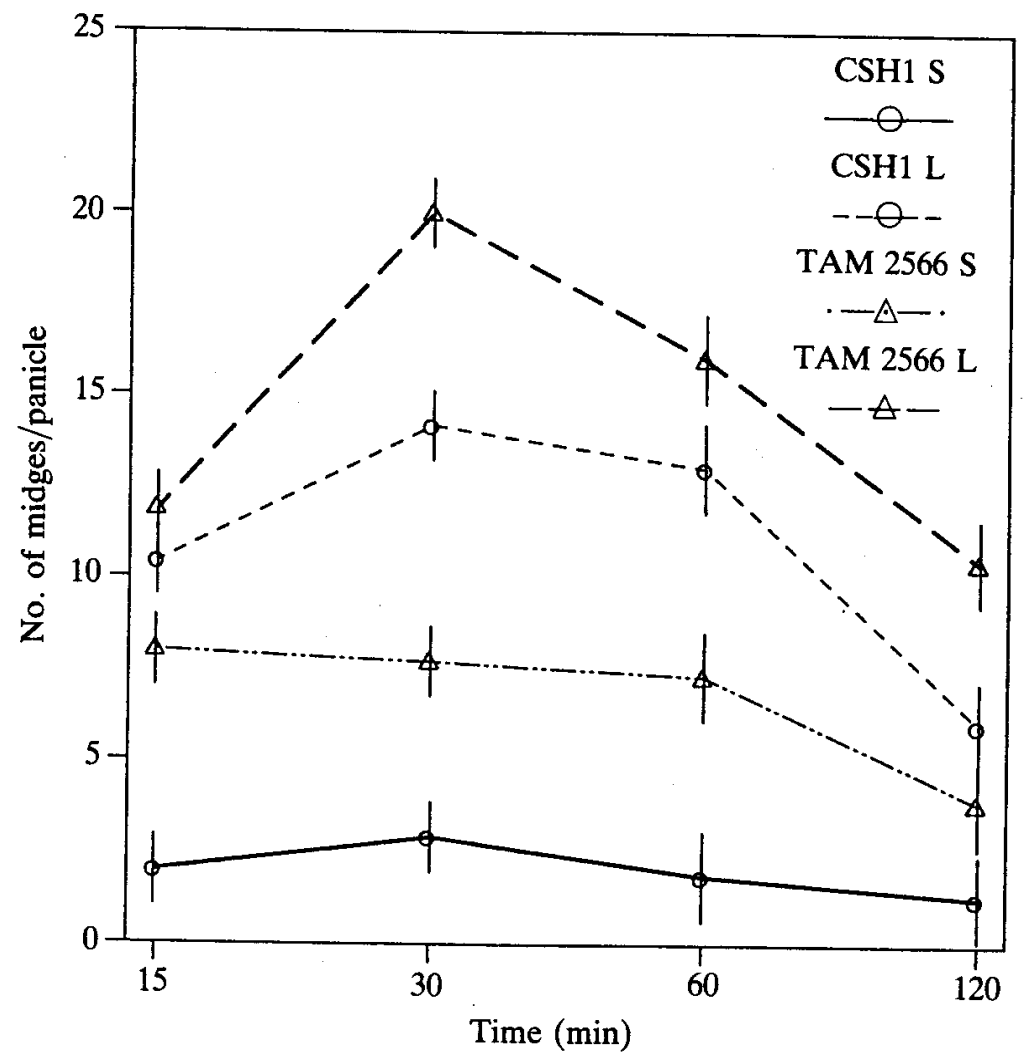

Fig. 4. Midge response towards large (L) vs small (S) panicles of CSH 1 and TAM 2566 at different intervals. 


\section{Results}

Effect of cage type and panicle size on orientation of midge females

More midges responded to the panicles of CSH 1 and TAM 2566 under cylindrical cage covered with a blue cloth bag compared with the mesh-screened wooden-cage (Fig. 3). However, the differences between the cages were significant only for TAM 2566.

Significantly more midges were recorded on the large panicles ( $>20$ branches/panicle) compared with small panicles (10 branches/panicle) of CSH 1 and TAM 2566 (Fig. 4). Numbers of midges recorded on the panicles decreased significantly 120 min after initiating the experiment. Hence, for antixenosis studies, data on midge response should be recorded 30 and $60 \mathrm{~min}$ after initiating the experiment.

Antixenosis mechanism of resistance in diverse sources of resistance to midge

\section{Multi-choice field conditions}

Under multi-choice field conditions, ICSV 197 and TAM 2566 were less preferred than the susceptible hybrids, CSH 1 and CSH 11 (Table 1). Numbers of midges on the panicles of DJ 6514 were also lower than CSH 1, but the differences were non-significant. More midges were recorded on ICSV 745 and CSH 11 than on CSH 1.

\section{Multi-choice cage tests}

Under multi-choice cage tests, in which the test cultivars were exposed to the midges under uniform insect pressure, IS 3461, AF 28 and DJ 6514 were less preferred than the susceptible controls CSH 1 and CSH 11 (Table 1). Numbers of midges on sorghum panicles decreased at $60 \mathrm{~min}$ compared to $30 \mathrm{~min}$ after initiating the experiment. ICSV 197 and TAM 2566, which showed antixenosis in the field, did not differ significantly from CSH 1 in cage tests.

Table 1. Cultivar antixenosis by the females of $\mathrm{C}$. sorghicola towards 10 sorghum genotypes under multi-choice conditions (ICRISAT Center, 1989-90 post-rainy season)

$\begin{array}{lccc}\quad \text { Genotype } & \overbrace{30 \mathrm{~min}}^{\begin{array}{c}\text { Multi-choice cage conditions } \\ \text { No. of midges/panicle after }\end{array}} & 60 \mathrm{~min} & \begin{array}{c}\text { Field conditions } \\ \text { No. of midges/ } \\ 10 \text { panicles }\end{array} \\ \text { IS 3461 } & 2.60(1.38)^{*} & 0.60(0.47) & 49.00(7.00) \\ \text { IS 10712 } & 8.70(2.75) & 3.30(1.66) & 71.50(7.67) \\ \text { ICSV 112 } & 8.40(2.54) & 6.30(2.37) & 51.50(7.04) \\ \text { ICSV 197 } & 9.60(2.99) & 6.40(2.25) & 19.50(4.24) \\ \text { ICSV 745 } & 9.56(2.91) & 4.90(2.04) & 140.00(11.43) \\ \text { TAM 2566 } & 7.10(2.53) & 4.30(1.97) & 23.00(4.65) \\ \text { AF 28 } & 3.80(1.58) & 1.40(0.77) & 56.00(7.45) \\ \text { DJ 6514 } & 4.90(1.87) & 1.60(0.87) & 40.00(6.32) \\ \text { CSH 1 } & 9.20(9.10) & 6.40(2.42) & 60.00(7.48) \\ \text { CSH 11 } & 12.83(3.29) & 6.50(2.31) & 112.00(10.47) \\ \text { SE } & \pm(0.389) & \pm(0.362) & \pm(0.109) \\ \text { CV (\%) } & 35.30 & 47.20 & 27.40\end{array}$

*Figures in parentheses are square root transformed values. 

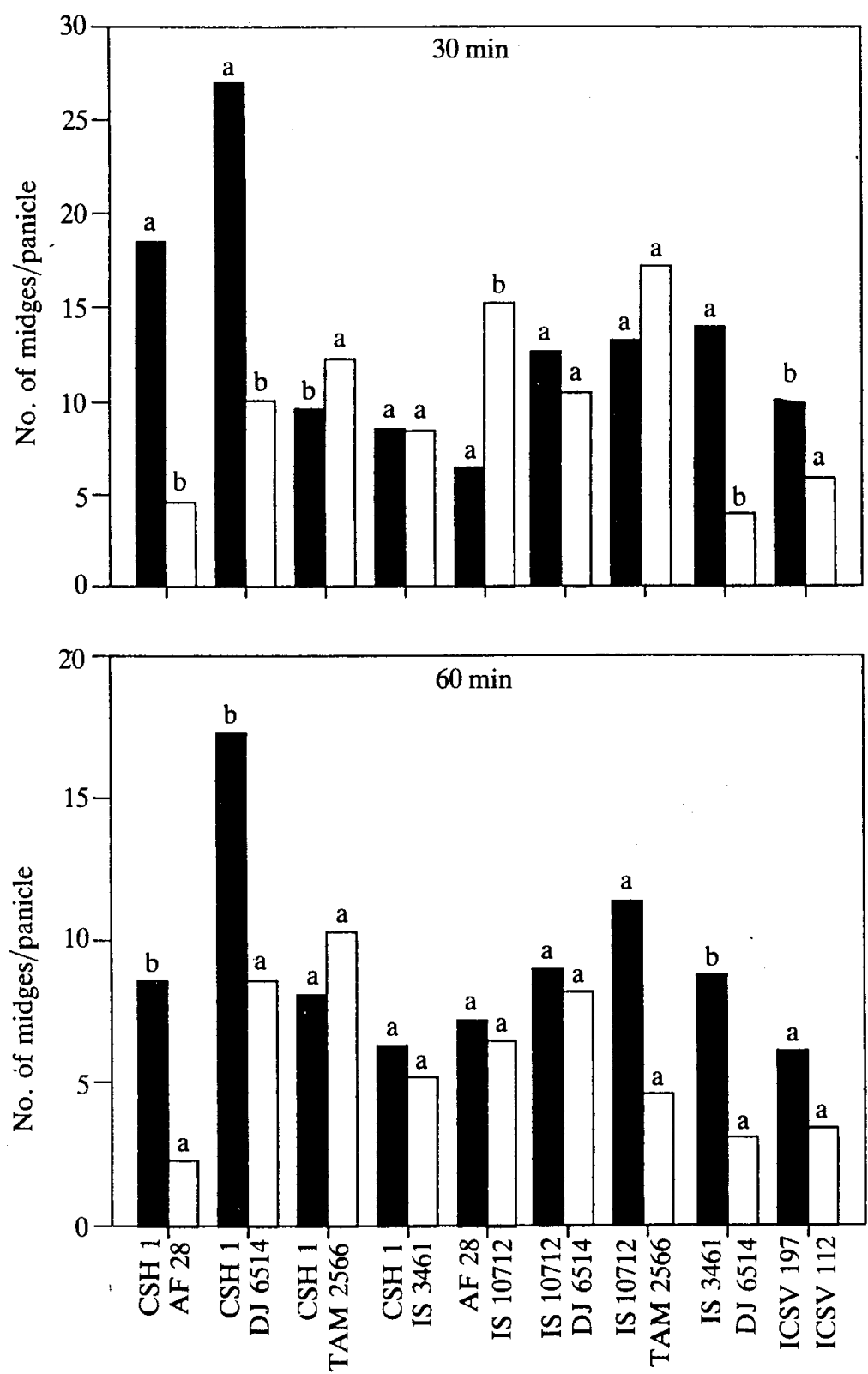

Fig. 5. Midge response towards different sorthum genotypes under double-choice cage tests. A pair of bars followed by the same letter are not significantly different at $P=0.05$.

\section{Double-choice tests}

In double-choice tests, where the relative preference of the test cultivars was studied in relation to each other in different combinations, AF 28 and DJ 6514 were significantly less preferred than CSH 1 (Fig. 5). TAM 2566 and IS 10712 did not differ significantly from CSH 1. AF 28 and DJ 6514 were also less preferred than IS 10712. The relative preference between IS 3461 vs DJ 6514 and ICSV 197 vs ICSV 112 changed over time. IS 10712 and TAM 2566 did not differ significantly from each other. DJ 6514 was significantly less preferred than IS 3461 .

\section{No-choice conditions}

Under no-choice conditions (in which the panicles of only a single cultivar were exposed to the midge females), 11, 20 and 12 midges were recorded on the panicles of TAM 2566, 
IS 10712 and CSH 1, respectively $30 \mathrm{~min}$ after the initiation of the experiment. At $60 \mathrm{~min}$, there were 6, 17 and 5 midges per panicle on TAM 2566, IS 10712, and CSH 1, respectively. Significantly greater numbers of midges responded to the panicles of IS 10712 compared with CSH 1 and TAM $2566(P=0.05, \mathrm{df}=18)$.

\section{Effect of cytoplasmic male-sterility on antixenosis to midge}

\section{Multi-choice field conditions}

Under multi-choice field conditions, more midges were recorded on the panicles of ICSA 42 and 296 than on PM 7061 and PM 7068 (Table 2). The differences between A- and Blines of the same cultivar were not significant.

\section{Multi-choice cage tests}

Under multi-choice cage tests, significantly more midges were recorded on the panicles of ICSA 42 and 296A compared with PM 7061A and PM 7068A (Tables 3 and 4). A similar

Table 2. Antixenosis by the females of $\mathrm{C}$. sorghicola towards $A$ and $B$ lines of four sorghum genotypes under field and multi-choice cage conditions (ICRISAT Center, 1990-91 post-rainy season)

\begin{tabular}{lccc} 
Genotype & $\begin{array}{c}\text { Field conditions } \\
\text { No. of midges/ } \\
\text { 10 panicles }\end{array}$ & \multicolumn{2}{c}{$\begin{array}{c}\text { Multi-choice cage condition } \\
\text { No. of midges/panicle }\end{array}$} \\
\cline { 3 - 4 } PM 7068A & 3.8 & $47.5(6.52)^{*}$ & $75.3(8.44)$ \\
PM 7068B & 2.6 & $56.4(6.85)$ & $55.3(7.10)$ \\
PM 7061A & 4.8 & $31.5(5.44)$ & $35.1(5.71)$ \\
PM 7061B & 2.6 & $47.7(6.44)$ & $47.3(6.63)$ \\
ICSA 42 & 6.8 & $44.0(6.29)$ & $57.1(6.98)$ \\
ICSB 42 & 5.6 & $44.6(6.24)$ & $41.8(6.22)$ \\
296A & 8.0 & $59.5(7.28)$ & $58.1(7.40)$ \\
296B & 6.3 & $38.0(5.95)$ & $63.5(7.60)$ \\
SE & \pm 1.38 & $\pm(0.688)$ & $\pm(0.549)$ \\
CV\% & 61.1 & $(34.1)$ & $(24.8)$
\end{tabular}

${ }^{*}$ Figures in parentheses are square root transformed values.

Table 3. Antixenosis by the females of C. sorghicola towards $A$ (male-sterile) and B (maintainer) lines of four sorghum genotypes (ICRISAT Center, 1989/90 post-rainy season)

\begin{tabular}{lcccc} 
Genotype & $\overbrace{30 \mathrm{~min}}$ & $60 \mathrm{~min}$ & & \multicolumn{2}{c}{ B lines } \\
PM 7061 & $14.2(3.42)^{*}$ & $11.8(3.13)$ & $20.8(4.02)$ & $15.6(3.52)$ \\
PM 7068 & $20.6(4.08)$ & $21.1(3.80)$ & $16.3(3.66)$ & $20.6(3.93)$ \\
ICSA 42 & $35.1(5.06)$ & $30.2(4.46)$ & $29.5(4.71)$ & $26.3(4.41)$ \\
296 & $35.3(5.39)$ & $34.1(5.28)$ & $31.9(5.36)$ & $35.7(5.53)$ \\
SE & $\pm(0.673)$ & $\pm(0.733)$ & $\pm(0.539)$ & $\pm(0.496)$ \\
CV (\%) & $(33.60)$ & $(39.30)$ & $(27.20)$ & $(25.50)$
\end{tabular}

${ }^{*}$ Figures in parentheses are square root transformed values. 
Table 4. Antixenosis by the females of C. sorghicola towards $A$ (male-sterile) and $B$ (maintainer) lines of four sorghum genotypes under multi-choice cage conditions (1990-91 post rainy season)

No. of midges/panicle

\begin{tabular}{|c|c|c|c|c|}
\hline \multirow[b]{2}{*}{ Genotype } & \multicolumn{2}{|c|}{ A lines } & \multicolumn{2}{|c|}{ B lines } \\
\hline & $30 \mathrm{~min}$ & $60 \mathrm{~min}$ & $30 \mathrm{~min}$ & $60 \mathrm{~min}$ \\
\hline PM 7068 & $17.0(4.08)^{*}$ & $17.0 \quad(3.96)$ & $80 \quad(8.78)$ & $103(10.03)$ \\
\hline PM 7061 & $17.0(3.98)$ & $17.0 \quad(4.10)$ & $27 \quad(5.11)$ & $34 \quad(5.75)$ \\
\hline ICSA 42 & $67.0(7.99)$ & $74.0 \quad(8.46)$ & $66 \quad(7.74)$ & 68 (7.94) \\
\hline 296 & $109.0(9.91)$ & $128.0(11.26)$ & $121(10.70)$ & $159(12.46)$ \\
\hline $\mathrm{SE}$ & $\pm(0.602)$ & $\pm(0.367)$ & $\pm(0.655)$ & $\pm(0.545)$ \\
\hline SV & (29.3) & $(16.7)$ & $(25.6)$ & $(19.0)$ \\
\hline
\end{tabular}

${ }^{*}$ Figures in parentheses are square root transformed values.

trend was observed for the B lines. However, the differences between PM 7068B and ICSB 42 were not significant. When both $\mathrm{A}$ and $\mathrm{B}$ lines were tested together, more midges responded to B lines $30 \mathrm{~min}$ after initiating the experiment (except for 296), and the differences between genotypes were not significant (Table 2). At $60 \mathrm{~min}$ after initiating the experiment, PM 7061A was significantly less preferred than 296A.

\section{Double-choice cage tests}

Under double-choice conditions, when the A and B lines of the same genotype were offered to the midge females, more midges responded to $B$ lines than to the $A$ lines of $\mathrm{PM}$ 7068 and ICSA 42 (Fig. 6) during the 1989-90 post-rainy season. Differences between A and B pairs were not significant for 296 and PM 7061. During the 1990-91 post-rainy season, more midges were recorded in the B lines of PM 7061 and 296 while the differences between A and B pairs were not significant for PM 7068 and ICSA 42.

\section{Discussion}

Cage tests using uniform insect pressure, and under similar environmental conditions were quite useful to study the nature and contribution of antixenosis component of resistance to $C$. sorghicola. Such tests have been found to be useful to study antixenosis in sorghum to Calocoris angustatus Leth. (Sharma \& Lopez, 1990). Midge response to sorghum panicles is influenced by the size of the panicle and type of confinement cage used to study the midge behaviour. The colour of the cloth bags used to cover the cage also influences midge behaviour (Sharma et al., 1988a). Hence, it is important to use standard and uniform conditions to study antixenosis component of resistance to sorghum midge. Midge response towards sorghum panicles peaked at 30 and $60 \mathrm{~min}$ initiating the experiment, and hence it is important to record insect numbers at these time intervals.

Low midge response towards ICSV 197 and TAM 2566 under field conditions was not confirmed under cage tests. Antixenosis by the midge females for IS 3461, AF 28 and DJ 6514 was also confirmed under cage tests. IS 10712 was preferred both under field and cage tests. DJ 6514 and AF 28 have earlier been reported to be preferred by the midge females under free-choice conditions in the field, while TAM 2566 is non-preferred (Sharma $e t a l$., $1988 a$ ). Because of the day to day variation in midge populations, staggered flowering of 

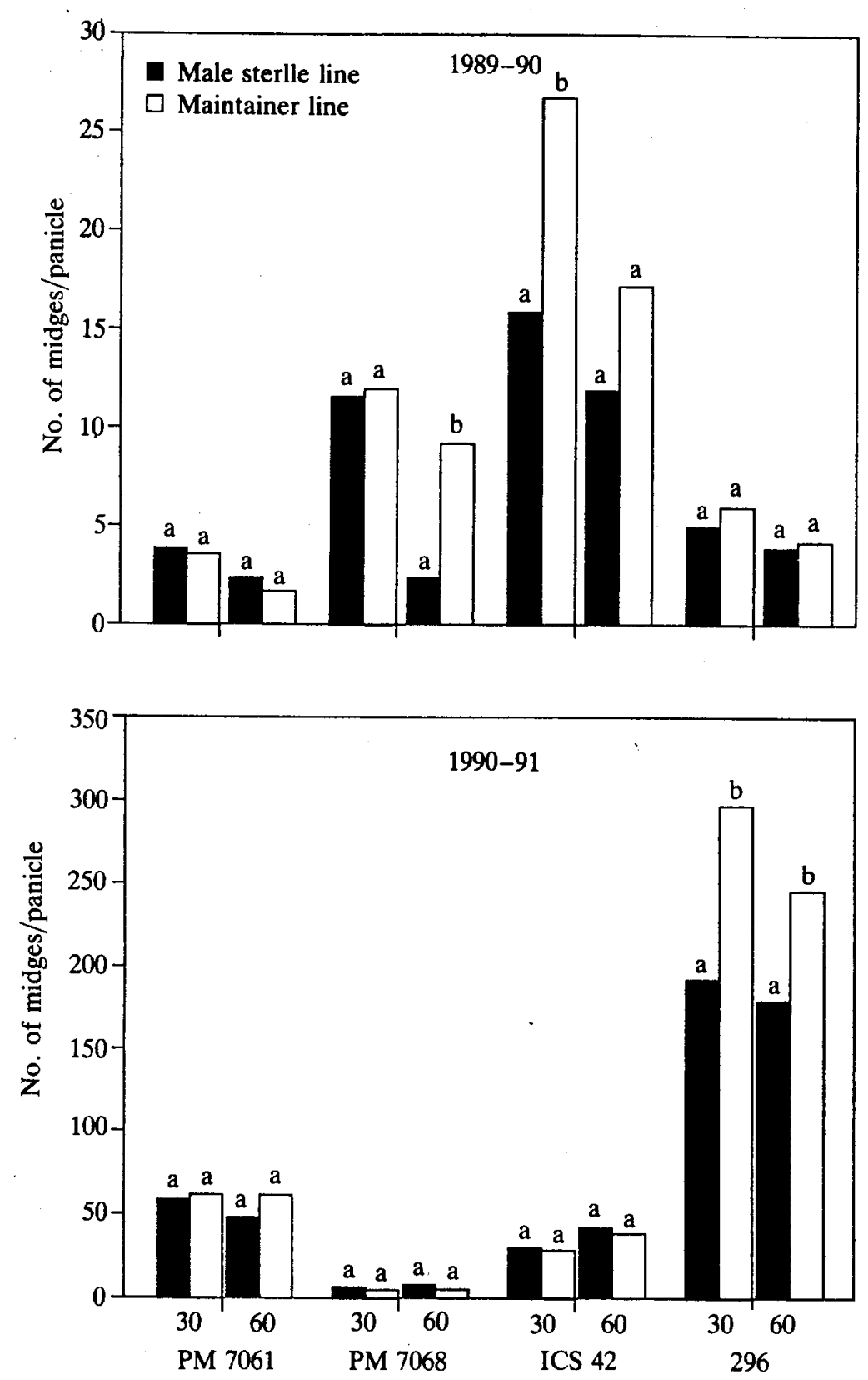

Fig. 6. Midge response towards male-sterile (a) vs maintainer $(b)$ lines of two midge-resistant (PM 7061 and PM 7068) and two midge-susceptible (296 and ICSA 42) female parents. A pair of bars at each observation interval for a genotype are not significantly different at $P=0.05$.

sorghum cultivars, and changes in environmental conditions (which affect the emergence and oviposition behaviour of $C$. sorghicola) (Fischer \& Teetes, 1982; Sharma \& Vidyasagar, 1992), it is difficult to obtain a realistic estimate of the antixenosis component of resistance under field conditions. Because of these problems, some cultivars showing resistance to sorghum midge under field conditions, become susceptible in the following seasons, under high midge density or under no-choice cage conditions (Sharma et al., 1988a).

Comparisons between the male-sterile (A-lines) and maintainer (B-lines) lines indicated that the differences in relative preference of $A$ and $B$ lines were not consistent, although significantly more midges were recorded on the panicles of B-lines than on the corresponding A-lines, in one out of the two tests. Comparisons between midge-resistant and midge- 
susceptible A or B lines under multi-choice conditions indicated that midge-resistant lines were less preferred (except PM 7068 B during the 1991 post-rainy season) than the midgesusceptible female parents (ICSA 42 and 296). PM 7061 and PM 7068 were less preferred by the midges under field conditions, and non-preference of these cultivars was also confirmed in cage tests (except for PM 7068B). Greater correspondence for antixenosis between field observations and cage tests for these cultivars may be because of their similar flowering periods and plant heights, which affect the midge response under field conditions. A-lines have earlier been found to be non-preferred for ovisposition because of differences in physico-chemical stimuli from the anthers, which affect the oviposition behaviour of midge females (Sharma et al., 1990a). However, male sterility did not seem to influence the orientation behaviour and acceptance of the host plant by $C$. sorghicola, although in one out of two tests, more midges responded to B lines compared with the corresponding A lines.

Midge-resistant lines have different combinations of factors conferring resistance to $C$. sorghicola (Sharma et al., 1991). Therefore, it is important to identify lines having antixenosis as a stable component of resistance to sorghum midge. Such lines can be used in the breeding programme to increase the levels and diversify resistance to this insect. This will be helpful to prolong the life of resistant cultivars when deployed under field conditions over large areas.

\section{Conclusion}

Orientation and acceptance of the host-plant by the females of $C$. sorghicola is influenced by several physical and environmental factors. Cage tests can help to determine and confirm the antixenosis to sorghum midge observed under field conditions. Double-, multi- and nochoice cage tests can also be useful to determine the relative preference and stability of antixenosis component of resistance to sorghum midge. IS 3461, AF 28 and DJ 6514 showed antixenosis to midge both under field and cage conditions. Male-sterility did not seem to influence antixenosis to midge, although significantly lower numbers of midges responded to the male-sterile lines than the maintainer lines in one out of two tests.

\section{Acknowledgements}

We thank Mr D Krishna and Mr V V Rao for their help in the field studies, Mr G Venkateswarlu for help in drawing the figures, and Dr D E Byth for his critical comments on the manuscript. Approved as J.A No 1478 by the International Crops Research Institute for the Semi-Arid Tropics (ICRISAT), Patancheru, Andhra Pradesh 502 324, India.

\section{References}

Bergquist R R, Rotar P, Mitchell W C. 1974. Midge and anthracnose head blight resistance in sorghum. Tropical Agriculture (Trinidad) 54:431-435.

Fischer R W, Teetes G L. 1982. Effect of moisture on sorghum midge (Diptera: Cecidomyiidae) emergence. Environmental Entomology 11:946-948.

Harris K M. 1976. The sorghum midge. Annals of Applied Biology 84:114-118.

Johnson J W, Rosenow D T, Teetes G L. 1973. Resistance to the sorghum midge in converted exotic sorghum cultivars. Crop Science 13:754-755. 
Peterson G C, Johnson J W, Teetes G L, Rosenow D T. 1988. Registration of midge resistant sorghum germplasm. Crop Science 25:372.

Rossetto C J. 1985. Sorghum midge: Host plant resistance mechanisms. Proceedings, International Sorghum Entomology Workshop, 15-21 July 1984, pp. 293-300. Patancheru, Andhra Pradesh 502 324, India: International Crops Research Institute for the Semi Arid Tropics (ICRISAT).

Rossetto C J, Goncalves W, Diniz J L M. 1975. Resistancia da variedada AF 28 a Mosca do sorgho, Na Ausencia da Qutras Variedades. Anais da Sociedade Entomologica do Brazil 4:16-20.

Sharma H C, Lopez V F. 1990. Mechanisms of resistance to sorghum head bug, Calocoris angustatus. Entomologia experimentalis et applicata 57:285-294.

Sharma H C, Vidyasagar P. 1992. Orientation of sorghum midge, Contarinia sorghicola males to sex pheromones from virgin females in the field. Entomologia experimentalis et applicata 64:23-29.

Sharma H C, Leuschner K, Vidyasagar P. 1990a. Factors influencing oviposition behavior of the sorghum midge, Contarinia sorghicola Coq. Annals of Applied Biology 116:431-439.

Sharma H C, Vidyasagar P, Leuschner K. 1988a. No-choice technique to screen for resistance to sorghum midge (Diptera: Cecidomyiidae). Journal of Economic Entomology 81:415-422.

Sharma H C, Vidyasagar P, Leuschner K. 1988b. Field screening for resistance to sorghum midge (Diptera: Cecidomyiidae). Journal of Economic Entomology 81:327-334.

Sharma H C, Vidyasagar P, Leuschner K. 1990b. Components of resistance to sorghum midge, Contarinia sorghicola. Annals of Applied Biology 116:327-333.

Sharma H C, Vidyasagar P, Leuschner K. 1991. Componental analysis of the factors influencing resistance to sorghum midge, Contarinia sorghicola Coq. Insect Science and its Application 11:889-
898 .

Singh B U. 1987. Varietal resistance in sorghum to midge, Contarinia sorghicola Coquillett (Diptera: Cecidomyiidae). Insect Science and its Application 8:129-144.

Teetes G L, Johnson J W. 1978. Insect resistance in sorghum. Proceedings, Thirty-third Annual Corn and Sorghum Research Conference, 12-14 December 1978, pp. 167-189. Chicago, Illinois, USA, Washington D.C., USA: American Seed Trade Association.

Waquil J M, Teetes G L, Peterson G C. 1986a. Sorghum midge (Diptera: Cecidomyiidae) oviposition behavior on resistant and susceptible sorghum hybrids. Journal of Economic Entomology 79:530532.

Waquil J M, Teetes G L, Peterson G C. 1986b. Comparison of immature sorghum midge (Diptera: Cecidomyiidae) development on resistant and susceptible sorghums. Journal of Economic Entomology 79:833-837.

Wiseman B R, McMillian W W. 1968. Resistance in sorghum to sorghum midge, Contarinia sorghicola (Coquillett) (Diptera: Cecidomyiidae). Journal of the Entomological Society of Georgia 3:147.

Wiseman B R, Duncan R R, Widstrom N W. 1988. Registration of SGIRL-MR-3 and SGIRL-MR-4 midge resistant sorghum germplasms. Crop Science 28:202-203.

Wiseman B R, McMillian W W, Widstrom N W. 1973. Registration of SGIRL-MR-1 sorghum germplasm. Crop Science 13:398.

(Received 1 April 1993) 